Research Article

\title{
Investigation of the Road Performance of AH-30 Bitumen and Its Mixture: Comparison with AH-70 and SBS-Modified Bitumen
}

\author{
Chenfeng Chu $\mathbb{D}^{1}{ }^{1}$ Jing $\mathrm{Zhu}^{2}$, and Zi-ang Wang ${ }^{3}$ \\ ${ }^{1}$ Wuhan Comprehensive Transportation Research Co. LTD, Wuhan 430014, China \\ ${ }^{2}$ Central Southern China Municipal Engineering Design and Research Institute Co. LTD, Wuhan 430010, China
}

${ }^{3}$ Changsha University of Science and Technology, Changsha 410114, China

Correspondence should be addressed to Chenfeng Chu; chuchenfeng_wh@sina.com

Received 18 July 2021; Accepted 29 November 2021; Published 31 December 2021

Academic Editor: Robert Černý

Copyright (c) 2021 Chenfeng Chu et al. This is an open access article distributed under the Creative Commons Attribution License, which permits unrestricted use, distribution, and reproduction in any medium, provided the original work is properly cited.

\begin{abstract}
$\mathrm{AH}-30$ is a type of high-viscosity matrix asphalt. The asphalt mixture made by AH-30 as a binder has an excellent antirutting performance. However, the other road performance of AH-30 was still worthy of attention. This research aims to reveal the properties of AH-30 and its impact on the road performance of asphalt mixtures (AH30-AC20/25). The AH-70 neat asphalt and SBS modified asphalt were prepared for comparison. The high-temperature sensitivity and fatigue resistance of AH-30 are evaluated by the dynamic shear rheological (DSR) test. The low-temperature performance is evaluated by the bending beam rheometer (BBR) test. The high-temperature stability (HTS) of AH30-AC20/25 is carried out by the wheel tracking (WT) test and the repeated shear constant height (RSCH) test. The low-temperature crack resistance (LTCR) is carried out by the direct stretching (DS) test. The fatigue property is carried out by the three-point bending test. Water stability (WS) is carried out by the Marshall residual stability (MRS) and the intensity ratio of the frozen and melted (IRFM) test. The test results show that the high-temperature resistance of AH-30 is better than that of AH-70. The low-temperature crack resistance of $\mathrm{AH}-30$ is equivalent to that of $\mathrm{AH}-70$. The $\mathrm{AH}-30$ as a binder can meet the requirements of the roads, which are located at a minimum temperature of not less than $-10.5^{\circ} \mathrm{C}$ in winter. The fatigue property of the $\mathrm{AH}-30$ asphalt mixture is poor, which may be one reason why $\mathrm{AH}-30$ asphalt pavement is more prone to cracking. The water stability of the $\mathrm{AH} 30-\mathrm{AC}$ (20/25) asphalt mixture can meet the specification requirements, and AH30-AC20 is better than the other two asphalt mixtures. The research of this paper will provide a basis and reference for the popularization and application of AH-30 in asphalt pavement.
\end{abstract}

\section{Introduction}

With the rapid growth of traffic, rutting in an asphalt pavement has gradually become one of the main problems that plague civil engineers in various countries [1-3]. Especially in the summer, the asphalt mixture is heated and softened, and the asphalt pavement resistance to deformation is reduced under high temperatures. Under the action of the longitudinal shear stress of the vehicle tires, the pavement will undergo irreversible deformation, which is also the main reason for rutting [4-6]. Rutting not only affects the driving comfort but also seriously endangers the driving safety. The water on the asphalt pavement cannot be removed quickly on rainy days with rutting. The vehicles are prone to drift when driving at high speeds on rainy days $[7,8]$.

Many scholars have done much work to improve the rutting problem of the asphalt pavement under heavy traffic conditions [9-11]. As an essential part of the asphalt mixture, asphalt plays a decisive role in rutting formation [12]. Therefore, to ensure the other road performance of the asphalt mixture (such as LTCR, water damage resistance, fatigue property, etc.), improving the high-temperature resistance of asphalt has become the main focus of the research [13, 14]. For example, the SBS-modified asphalt widely used currently has excellent road performance. 
However, with the advancement of technology, some studies are also trying to find other better solutions. Jamal and Giustozzi [15] proposed a low-content crumb rubbermodified bitumen, and the results of multiple stress creep recovery tests show that the modified asphalt can improve the rutting resistance of asphalt pavements. Some studies have also improved the high-temperature performance of asphalt by adding nanomaterials [16, 17]. The test results show that the addition of nanomaterials effectively improves the high-temperature resistance of asphalt and mixtures, while the LTCR and aging resistance are also improved.

Modified asphalt does have many advantages in improving road performance, however, there are also some problems. For example, in the construction process of asphalt pavement, the SBS-modified asphalt faces three major technical defects: heat aging, segregation, and thermal decomposition during processing and storage. It results in various quality variations that often occur before construction and more significantly impacts construction quality. A survey report published by the Ministry of Transport of China in 2015 shows that the modified asphalt's qualified quality sampling rate is only $66.7 \%$.

As a kind of matrix asphalt with high viscosity and high modulus, AH-30 can increase the middle and lower layers of the pavement and effectively reduce its rutting problem [18]. However, there are a few studies on AH-30. Tong [19] et al. conducted the preparation and evaluation of $\mathrm{AH}-30$ by blending it with various soft components. The results of the mix performance tests showed that $\mathrm{AH}-30$ had excellent anti-high-temperature deformation ability and preferable water stability compared with high-grade asphalt. Wang [20] et al. studied the fatigue performance of modified hard-grade asphalt. The results showed that the antifatigue performance of the SBS-modified hard-grade asphalt was better, however, the author did not conduct in-depth research on other properties. Therefore, this study conducted the related tests on the road performance of $\mathrm{AH}-30$ and studied the possibility of AH-30 as a binder for asphalt mixtures. The research results are expected to provide a reference for the research and application of $\mathrm{AH}-30$ hard asphalt.

\section{Objectives}

To understand the AH-30 and road performance of its mixture. Road performance (high-temperature, low-temperature, fatigue performance, and water stability) comparison tests were carried out on AH-30, neat asphalt (AH-70), SBS-modified asphalt, and asphalt mixture. The research results will provide a basis and reference for the popularization and application of $\mathrm{AH}-30$ on asphalt pavement.

\section{Materials and Test Methods}

3.1. Asphalt. In this research, AH-30 is the main research object. AH-70 and SBS-modified asphalt are the comparison items. The AH-30 and AH-70 are all of grade A and produced by China Overseas Asphalt (Taizhou) Co., Ltd in Shang Dong, China. The 1301 linear SBS modifier provided by the Yueyang Petrochemical Complex Co., Ltd. was selected to modify the bitumen. The main specifications are shown in Table 1. The type of SBS-modified asphalt is I-D. The test method refers to the Chinese standard JTG E202011. The test results of the three asphalts are shown in Table 2.

3.2. Aggregate. In this study, two different aggregates were used. The coarse aggregate is basalt produced in Luoyang City, and the fine aggregate is limestone produced in Zhumadian City, Henan Province, China. The two aggregates were tested according to the test method specified in the Chinese standard JTG E42-2005 (China DOT 2005). The test results of the coarse aggregate are shown in Table 3, whereas those of the fine aggregate are shown in Table 4.

3.3. Asphalt Mixtures. In this research, the gradations used in the asphalt mixture are AC-20 and AC-25. The gradation curves of these two gradations are shown in Figure 1. The design method of asphalt mixture is the Marshall method. The design results of the four asphalt mixtures: SBS-AC20, AH-30-AC20, AH30-AC25, and AH70-AC25, are shown in Table 5 .

\subsection{Test Methods}

3.4.1. Dynamic Shear Rheological Test. In this study, the DSR test was selected to evaluate the high-temperature sensitivity (original asphalt and aged by RTFOT) and antifatigue performance of asphalt. The high-temperature sensitivity test was carried out under six temperature conditions: $64^{\circ} \mathrm{C}$, $70^{\circ} \mathrm{C}, 76^{\circ} \mathrm{C}, 82^{\circ} \mathrm{C}, 88^{\circ} \mathrm{C}$, and $94^{\circ} \mathrm{C}$. Two indexes could be obtained from the test result to evaluate the high-temperature sensitivity of asphalt: phase angle $\delta$ and antirutting factor $G^{*} / \sin \delta$. The fatigue resistance of asphalt is evaluated by $G^{\prime \prime}=G^{*} \times \sin \delta$. The antifatigue performance test selects the asphalt aged by PAV, and the test temperature is $19^{\circ} \mathrm{C}$, $22^{\circ} \mathrm{C}$, and $25^{\circ} \mathrm{C}$, respectively.

3.4.2. Bending Beam Rheometer Test. The BBR test was selected to evaluate the low-temperature performance of asphalt. The stiffness modulus (SM) and creep rate (CR) can be obtained from the BBR test. Before conducting the BBR test, the asphalt was first aged by RTFOT, which simulated the aging of asphalt during construction. Then PAV aging simulates the asphalt pavement aging for five years. The size of the asphalt standard beam in the BBR test is $127 \pm 2 \mathrm{~mm} \times 12.7 \pm 0.05 \mathrm{~mm} \times 6.35 \pm 0.05 \mathrm{~mm}$, and the test is carried out at the temperature of $-6^{\circ} \mathrm{C},-12^{\circ} \mathrm{C}$, and $-18^{\circ} \mathrm{C}$, respectively.

3.4.3. WT and Repeated Shear Constant Height Tests. In this study, the WT and repeated shear constant height (RSCH) tests were selected to study the high-temperature stability of the asphalt mixture.

The method of wheel compaction is used to make the rutting slabs, and the size is $300 \mathrm{~mm} \times 300 \mathrm{~mm} \times 50 \mathrm{~mm}$. Before the WT test, the slabs need to be placed in a 
TABLe 1: Physical specifications of SBS modifier.

\begin{tabular}{lcccc}
\hline Volatile content (\%) & Melt flow rate $(\mathrm{g} / 10 \mathrm{~min})$ & Elongation at break (\%) & $\begin{array}{c}\text { Permanent deformation } \\
\text { rate at break (\%) }\end{array}$ & 300\% tensile strength (MPa) \\
\hline 0.70 & 1.80 & 720 & 28 & 2.0 \\
\hline
\end{tabular}

TABLE 2: Technical properties of asphalt.

\begin{tabular}{|c|c|c|c|c|c|c|c|}
\hline Test item & $\mathrm{AH}-30$ & $\begin{array}{l}\text { Technica } \\
\text { requirements }\end{array}$ & SBS & $\begin{array}{c}\text { Technical } \\
\text { requirements }\end{array}$ & $\mathrm{AH}-70$ & $\begin{array}{c}\text { Technical } \\
\text { requirements }\end{array}$ & $\begin{array}{c}\text { Test } \\
\text { method }\end{array}$ \\
\hline $\begin{array}{l}\text { Penetration }\left(25^{\circ} \mathrm{C}, 100 \mathrm{~g}, 5 \mathrm{~s}\right. \\
0.1 \mathrm{~mm})\end{array}$ & 26 & $20 \sim 40$ & 56 & $30 \sim 60$ & 65 & $60 \sim 80$ & T0604 \\
\hline Ductility: $5 \mathrm{~cm} / \mathrm{min}, 5 / 15^{\circ} \mathrm{C}(\mathrm{cm})$ & 43 & $\geq 50$ & $34\left(5^{\circ} \mathrm{C}\right)$ & $\geq 20$ & 113 & $\geq 100$ & T0605 \\
\hline Softening point, ring ball $\left({ }^{\circ} \mathrm{C}\right)$ & 60 & $\geq 55$ & 79 & $\geq 60$ & 50 & $\geq 46$ & T0606 \\
\hline Penetration index & -0.991 & $-1.5 \sim+1.0$ & 0.533 & $\geq 0$ & -0.476 & $-1.5 \sim+1.0$ & T0604 \\
\hline Viscosity at $60^{\circ} \mathrm{C}(\mathrm{Pa} \cdot \mathrm{s})$ & 1626 & $\geq 260$ & $\begin{array}{c}2.31 \\
\left(135^{\circ} \mathrm{C}\right)\end{array}$ & $\leq 3$ & 224 & $\geq 180$ & T0620 \\
\hline Paraffin content $(\%)$ & 0.6 & $\leq 2.2$ & - & - & 1.2 & $\leq 2.2$ & T0615 \\
\hline Solubility $(\%)$ & 99.7 & $\geq 99.5$ & 99.92 & $\geq 99$ & 99.8 & $\geq 99.5$ & T0607 \\
\hline Flash point $\left({ }^{\circ} \mathrm{C}\right)$ & 296 & $\geq 260$ & 267 & $\geq 230$ & 330 & $\geq 260$ & T0611 \\
\hline Density at $15^{\circ} \mathrm{C}\left(\mathrm{g} / \mathrm{cm}^{3}\right)$ & 1.022 & Actual test results & 1.032 & Actual test results & 1.012 & Actual test results & T0603 \\
\hline \multicolumn{8}{|c|}{ After rolling thin-film oven short-term aging test $\left(163^{\circ} \mathrm{C}, 5 \mathrm{~h}\right)$} \\
\hline Mass loss (\%) & 0.0 & $\leq \pm 0.8$ & 0.1 & $\leq \pm 1.0$ & -0.026 & $\leq \pm 0.8$ & T0610 \\
\hline Residual penetration ratio (\%) & 85 & $\geq 65$ & 73 & $\geq 65$ & 63 & $\geq 61$ & T0604 \\
\hline Residual ductility at $10^{\circ} \mathrm{C}(\mathrm{cm})$ & - & - & $16\left(5^{\circ} \mathrm{C}\right)$ & $\geq 15$ & 7 & $\geq 6$ & T0605 \\
\hline
\end{tabular}

TABLE 3: Technical properties of coarse aggregate.

\begin{tabular}{lccc}
\hline Test item & Technical requirements & Test result & Test method \\
\hline Crushed stone value (\%) & $\leq 28$ & 10.6 & T0316 \\
Los Angeles wearied stone value (\%) & $\leq 30$ & 11.5 & T0317 \\
Apparent relative density $\left(\mathrm{g} / \mathrm{cm}^{3}\right)$ & $\geq 2.5$ & 2.926 & 70304 \\
Water absorbency (\%) & $\leq 3.0$ & 1.17 & T0304 \\
Sturdiness (\%) & $\leq 12$ & 1.3 & T0314 \\
Soft stone content (\%) & $\leq 5$ & 0.4 & T0320 \\
\hline
\end{tabular}

TABle 4: Technical properties of fine aggregate.

\begin{tabular}{lccc}
\hline Test item & Technical requirements & Test result & Test method \\
\hline Apparent relative density $\left(\mathrm{g} / \mathrm{cm}^{3}\right)$ & $\geq 2.5$ & 2.721 & T0328 \\
Sturdiness $(0.3 \sim 4.75 \mathrm{~mm})(\%)$ & $\geq 12$ & 22 & T0340 \\
Soil content $(\%)$ & $\leq 3$ & 0.8 & T0333 \\
Sand-equivalent (\%) & $\geq 60$ & 85.2 & T0334 \\
Methylene blue number (g/kg) & $\leq 25$ & 3.7 & T0349 \\
Angularity (flow time) (s) & $\geq 30$ & 36.7 & T0345 \\
\hline
\end{tabular}

thermostat at $60^{\circ} \mathrm{C}$ for 6 hours. During the WT test, the pressure of the wheel is $0.7 \mathrm{MPa}$, the walking distance is $230 \mathrm{~mm} \pm 10 \mathrm{~mm}$, the walking speed is 42 times/min, and the walking direction is the same as the molding and rolling direction of the specimen.

The molding method of the specimens in the RSCH test is the gyration compaction, the size of the samples is $\Phi 100 \mathrm{~mm} \times 80 \mathrm{~mm}$, and the porosity is $4 \pm 0.5 \%$. Before conducting the RSCH test, the specimen shall be kept in a $60^{\circ} \mathrm{C}$ environmental box for $4 \mathrm{~h}$. During the test, the repetitive half-sine shear stress of $69 \mathrm{KPa}$ is applied. The load time is $0.1 \mathrm{~s}$, the unloading time is $0.6 \mathrm{~s}$, and the frequency is $1.43 \mathrm{~Hz}$. Such a circulate is called a cycle.
Stop the RSCH test when cycles reach 5000 or the shear strain reaches $5 \%$. In the $\mathrm{RSCH}$ test, as the number of repeated shearing increases, the asphalt mixture's permanent shear strain will tend to be stable. At this stage, the slope of the fitting curve is $k$, and the intercept is $b$. The smaller the values of $k$ and $b$ of the fitted curve, the better the hightemperature stability of the asphalt mixture.

3.4.4. Direct Stretching Test. The DS test is used to evaluate the crack resistance of the asphalt mixture at low temperatures. The specimen is a rectangular beam of $50 \mathrm{~mm} \times 50 \mathrm{~mm} \times 250 \mathrm{~mm}$, which is cut from the slabs by 


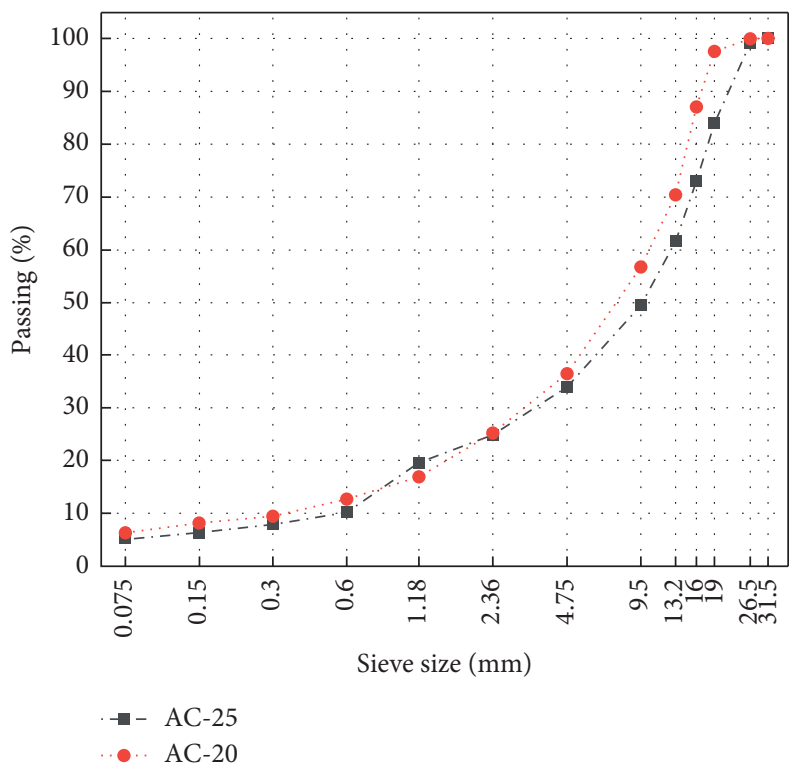

Figure 1: Aggregate gradation curves of asphalt mixtures.

TABle 5: Summary of Marshall design results of four types of asphalt mixtures.

\begin{tabular}{lcccccc}
\hline Technical index & AH70-AC25 & AH30-AC25 & AH30- AC20 & SBS-AC20 & Technical requirements & Test method \\
\hline Asphalt-aggregate ratio (\%) & 5.0 & 4.0 & 4.6 & 4.4 & - & - \\
Volume of air voids (\%) & 4.2 & 5.3 & 4.7 & 4.9 & $4-6$ & T0705 \\
Void in mineral aggregate (\%) & 13.7 & 15.2 & 14.7 & 14.2 & T0705 \\
Voids filled with asphalt (\%) & 73.5 & 61.2 & 68.6 & 65.6 & $65-75$ & T0705 \\
Marshall stability (kN) & 7.4 & 39.5 & 14.51 & 11.2 & T0709 \\
Flow value (0.1 mm) & 3.62 & 2.49 & 2.13 & 4.0 & $1.5-4$ & T0709 \\
\hline
\end{tabular}

roller compaction. The test was carried out at $5^{\circ} \mathrm{C},-5^{\circ} \mathrm{C}$, and $-15^{\circ} \mathrm{C}$, respectively. Three parallel tests were carried out at each test temperature, and the average value was calculated. The tensile rate of the specimen is $2 \mathrm{~mm} / \mathrm{min}$.

3.4.5. Three-Point Bending Test. In this study, a three-point bending fatigue test was used to study the fatigue resistance of the asphalt mixtures. The molding method and size of the specimens are the same as the DS test. Before the fatigue test, the strength test is carried out. The strength and fatigue test temperature is $15^{\circ} \mathrm{C}$, and the loading rate of the strength test is $2 \mathrm{~mm} / \mathrm{min}$. The fatigue test adopts the stress control mode. The loaded waveform is a continuous half-sine waveform of $10 \mathrm{~Hz}$. Equation (1) is the calculation method of the flexural tensile strength $R_{B}$ when the trabecular fails. To calculate the average flexural tensile strength, five specimens of each asphalt mixture are tested in parallel.

The DS and the three-point bending fatigue test use the MTS-810 material testing system produced by MTS Systems (China) Co., Ltd. for testing.

$$
R_{B}=\frac{3 \mathrm{LP}_{B}}{2 \mathrm{bh}^{2}}
$$

Here, $R_{B}$ is the bending tensile strength when the specimen is broken $(\mathrm{MPa}) ; b$ is the width of the crossinterrupted interview piece $(\mathrm{mm}) ; h$ is the height of the cross-interrupted interview piece $(\mathrm{mm}) ; L$ is the span of the test piece $(\mathrm{mm})$; and $P_{B}$ is the load when the specimen is broken $(\mathrm{N})$.

3.4.6. Marshall Residual Stability and IRFM Test. The MSR and IRFM tests carry out the WS of the asphalt mixture. The specimen molding method is the Marshall compaction (double-sided compaction 50 times), and the specimen size is $\Phi 101.6 \times 63.5 \mathrm{~mm}$. In the MSR test, the stability of a group (4 specimens) of specimens in hot water at $60^{\circ} \mathrm{C}$ for 30 minutes and that of the other in the water at $60^{\circ} \mathrm{C}$ for 48 hours is tested. The stability of the immersion residue of the parts is calculated according to equation (2):

$$
\mathrm{MS}_{0}=\frac{\mathrm{MS}_{1}}{\mathrm{MS}} \times 100 \% \text {. }
$$

Here, $\mathrm{MS}_{0}$ is the residual strength of the specimen in water (\%); $\mathrm{MS}_{1}$ is the stability of the specimen after being immersed in water for 48 hours $(\mathrm{kN})$; and MS is the stability of the specimen after being immersed in water for 30 minutes $(\mathrm{kN})$.

The IRFM test is carried out according to the following test procedure: one set of test pieces (4 specimens) is immersed in water at $25^{\circ} \mathrm{C}$ for 2 hours and subjected to a splitting strength test. The other set of specimens is immersed in water for 20 minutes at $25^{\circ} \mathrm{C}$. Then, it is immersed 
in water for 15 minutes in a vacuum box with a pressure of $0.09 \mathrm{MPa}$. It is kept at $-18^{\circ} \mathrm{C}$ for 16 hours and in a water bath at $60^{\circ} \mathrm{C}$ for 24 hours. It is immersed in water at $25^{\circ} \mathrm{C}$ for 2 hours before the test. Then, the splitting strength test was carried out on this group.

The splitting tensile strength $R_{1}, R_{2}$, and the splitting strength ratio TSR are calculated according to equations (3)-(5).

$$
\begin{aligned}
R_{1} & =\frac{0.006287 P_{1}}{h_{1}}, \\
R_{2} & =\frac{0.006287 P_{2}}{h_{2}}, \\
\mathrm{TSR} & =\frac{R_{2}}{R_{1}} \times 100 \% .
\end{aligned}
$$

Here, TSR is the splitting strength ratio (\%); $R_{1}$ is the splitting strength of the specimen without freezing and thawing cycles $(\mathrm{MPa}) ; R_{2}$ is the splitting strength of the specimen after freeze-thaw cycles $(\mathrm{MPa})$; and $P_{1}$ and $P_{2}$ are the maximum values $(\mathrm{N})$ of the test loads of the first and second groups, respectively.

\section{Result and Discussion}

\subsection{Test Result of Asphalt}

4.1.1. High-Temperature Sensitivity. The DSR test results of unaged asphalt are shown in Figure 2.

The greater the phase angle $(\delta)$, the greater the viscosity of asphalt. It means that the deformation that occurs after the asphalt is stressed is harder to recover, which means the high-temperature resistance is poor. It is observed from Figure 2(a) that at the same temperature, the $\delta$ of the SBS-modified asphalt is the smallest, followed by $\mathrm{AH}-30$. The $\delta$ of $\mathrm{AH}-70$ is the largest, which shows that the high-temperature resistance of $\mathrm{AH}-30$ is between that of SBS and AH-70.

Another index to evaluate the high-temperature sensitivity of asphalt is the antirutting factor $\left(G^{*} / \sin \delta\right)$. The larger the $G^{*} / \sin \delta$, the stronger the ability of asphalt to resist deformation at high temperatures. It is observed from Figure 2(b) that the $G^{*} / \sin \delta$ of the three asphalts decreases with the increase in temperature. It means that the hightemperature resistance of the three asphalts decreases with the increase in temperature. When the test temperature is $65^{\circ} \mathrm{C}$ (close to the actual temperature of the asphalt pavement during the hottest summer), the $G^{*} / \sin \delta$ of $\mathrm{AH}-30$ is significantly higher than the other two asphalts. Moreover, when the test temperature reaches $88^{\circ} \mathrm{C}$, similar to the SBSmodified asphalt, the $G^{*} / \sin \delta$ of AH-30 is still greater than $1.0 \mathrm{KPa}$. However, at this time, the antirutting factor of $\mathrm{AH}-$ 70 can no longer meet the requirements.

The DSR test results of asphalt before and after the RTFOT aging are shown in Figure 3.

It can be seen from Figure 3. After RTFOT aging, the phase angle $(\delta)$ of $\mathrm{AH}-30$ decreases, and the antirutting factor $\left(G^{*} / \sin \delta\right)$ increases. It proves that the aged AH-30 still has good high-temperature resistance. After a long-term operation after completion, the AH-30 pavement still has good rutting resistance.

4.1.2. Low-Temperature Performance. The results of the BBR test of the three asphalts are shown in Figure 4.

According to the Strategic Highway Research Program requirements, the $\mathrm{SM}$ of asphalt at low temperature should be less than $300 \mathrm{MPa}$, and the CR should be greater than $0.3 \mathrm{~mm}$. The lower the SM of asphalt, the better the LTCR. Conversely, the larger the CR, the better the LTCR of asphalt.

It is observed from Figure 4(a) that when the test temperature is $-12^{\circ} \mathrm{C}$, the $\mathrm{SM}$ of $\mathrm{AH}-30$ is larger than $300 \mathrm{MPa}$. At this temperature, $\mathrm{AH}-30$ can no longer meet the requirements. However, at this temperature, the SM of $\mathrm{AH}$ 70 and SBS-modified asphalt is less than $300 \mathrm{MPa}$. It can be seen from Figure 4(b) that when the temperature exceeds $-14^{\circ} \mathrm{C}$, the $\mathrm{CR}$ of $\mathrm{AH}-30$ cannot meet the requirements, while the CR of SBS-modified asphalt and AH-70 can meet the requirements.

Analyze the above test results and compare AH-30 with AH-70 or SBS-modified asphalt. When the temperature decreases, the index of AH-30 will not meet the requirements of LTCR first, which is related to less gum in AH-30.

When the temperature is higher than $-10.5^{\circ} \mathrm{C}$, the LTCR of AH-30 can meet the requirements. It means that in the southern part of North China (the average winter temperature is about $\left.-8^{\circ} \mathrm{C} \sim 0^{\circ} \mathrm{C}\right), \mathrm{AH}-30$ can be used as a binder when building roads because it can meet the requirements of road LTCR in winter.

4.1.3. Fatigue Resistance. The fatigue test results of the three asphalts after the PAV are shown in Figure 5.

At the same temperature, the smaller the $G^{*} \sin \delta$ value, the better the fatigue resistance of asphalt. It is observed from Figure 5 that at the same test temperature, the $G^{*} \sin \delta$ value of AH-30 is always the largest. The $G^{*} \sin \delta$ value of SBS-modified asphalt is always the smallest, which shows that $\mathrm{AH}-30$ has poor fatigue resistance, which may be one reason why $\mathrm{AH}-30$ pavements are more prone to cracking during long-term use.

\subsection{Test Result of Asphalt Mixture}

4.2.1. High-Temperature Stability. The test results of the WT test are shown in Figure 6. The test results of the RSCH are shown in Figure 7.

It is observed from Figure 6 that the high-temperature stability of the AH-30 asphalt mixture is affected by gradation. The dynamic stability of AH30-AC25 is approximately $20.3 \%$ greater than that of AH30-AC20. Under the gradation conditions and when compared to SBS and $\mathrm{AH}-70$ asphalt mixtures, the dynamic stability of AH30-AC20/25 is more efficient, which means that in the areas where the temperature is very high in summer, the $\mathrm{AH}-30$ asphalt 


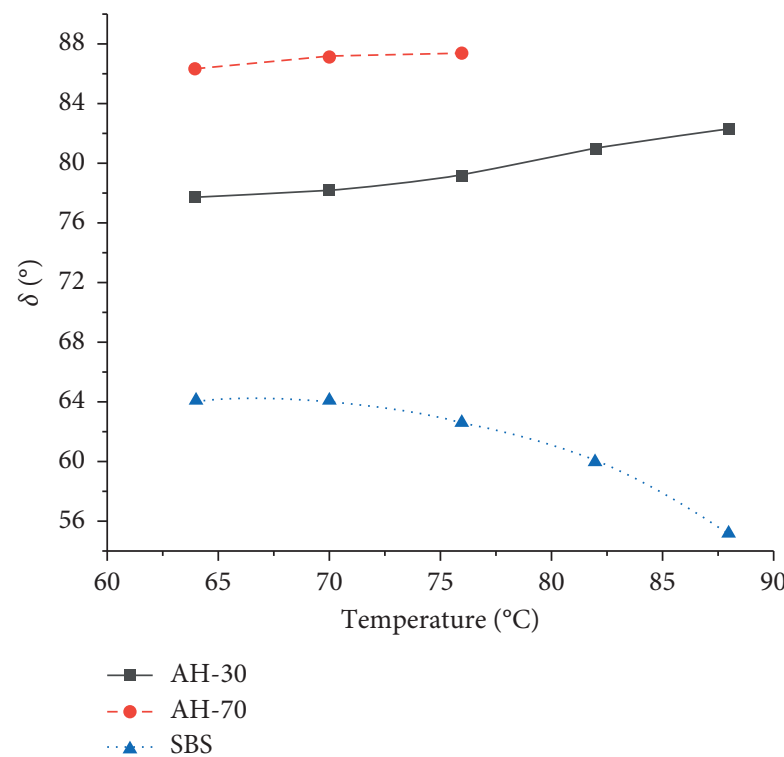

(a)

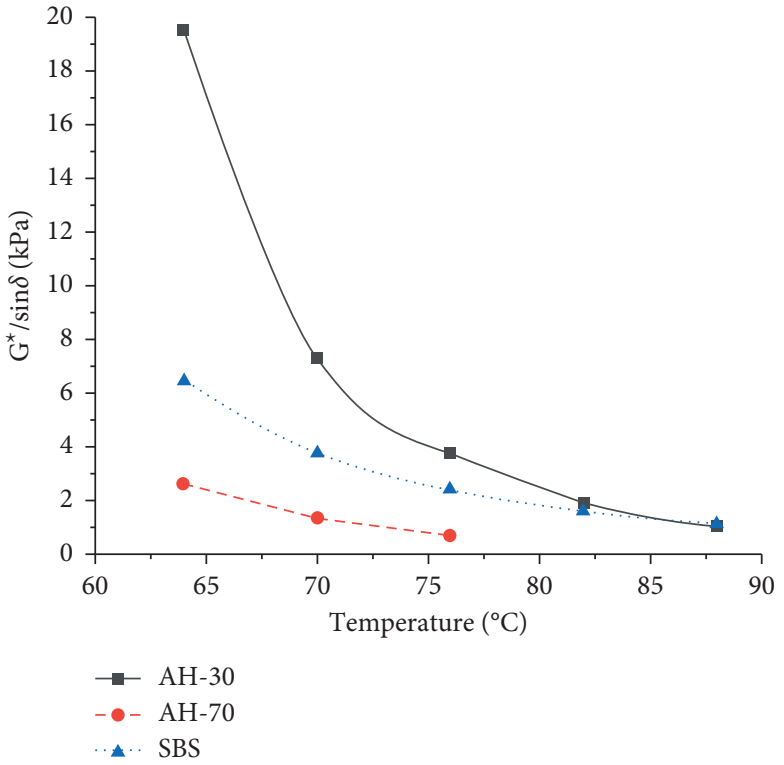

(b)

FIGURE 2: DSR test results of three asphalts: (a) phase angle and (b) antirutting factor.

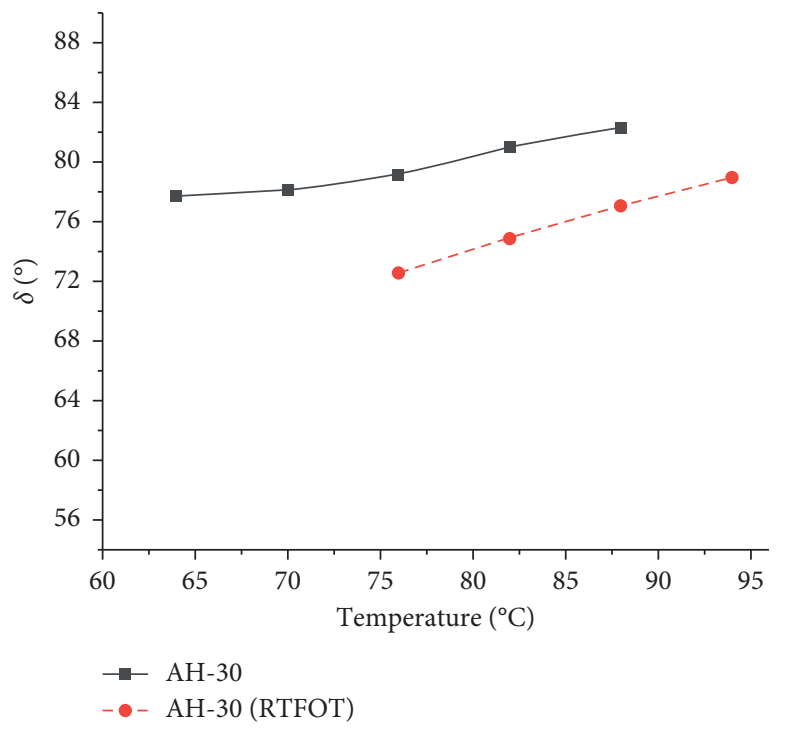

(a)

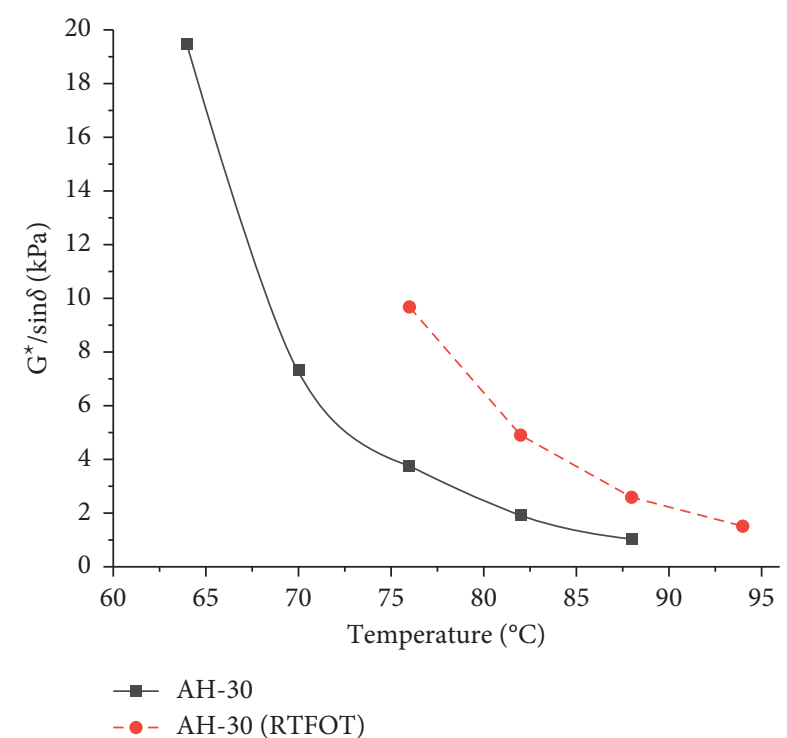

(b)

FIGURE 3: Comparison of high-temperature resistance of AH-30 before and after RTFOT aging: (a) phase angle and (b) antirutting factor.

mixture's high-temperature resistance is good. The antirutting performance is good, and the WT test results are consistent with the analysis results of the antirutting factor in the DSR test.

It is observed from Figure 7 that under the same conditions of gradation, the values of $k$ and $b$ of AH30-AC20/25 are smaller than those of AH-70 and SBS-modified asphalt mixtures. It also proves once again that AH-30 has excellent high-temperature resistance.
4.2.2. Low-Temperature Crack Resistance. Figure 8 shows the stress-strain test results of the DS test of the four asphalt mixtures at different temperatures.

It can be seen from Figure 8 that at $-15^{\circ} \mathrm{C}$ and $5^{\circ} \mathrm{C}$, the DS test results of the $\mathrm{AH}-30$ and $\mathrm{AH}-70$ asphalt mixtures are similar. At $-5^{\circ} \mathrm{C}$, the tensile strain of $\mathrm{AH}-30$ asphalt mixture is slightly larger than that of $\mathrm{AH}-70$ asphalt mixture, and at $-5^{\circ} \mathrm{C}$, the stress-strain results of $\mathrm{AH} 30-\mathrm{AC} 25$ are close to those of SBS-AC20. 


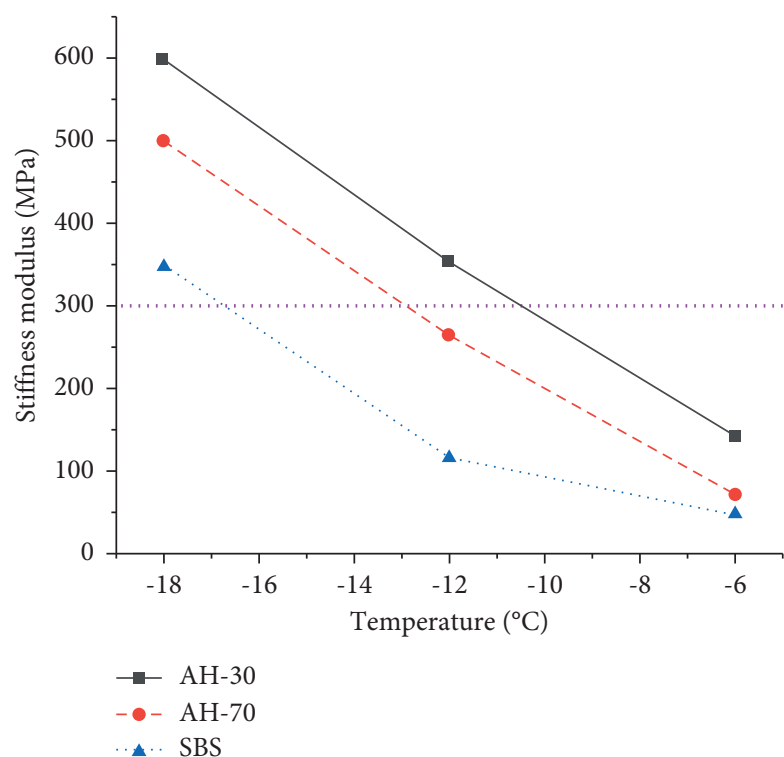

(a)

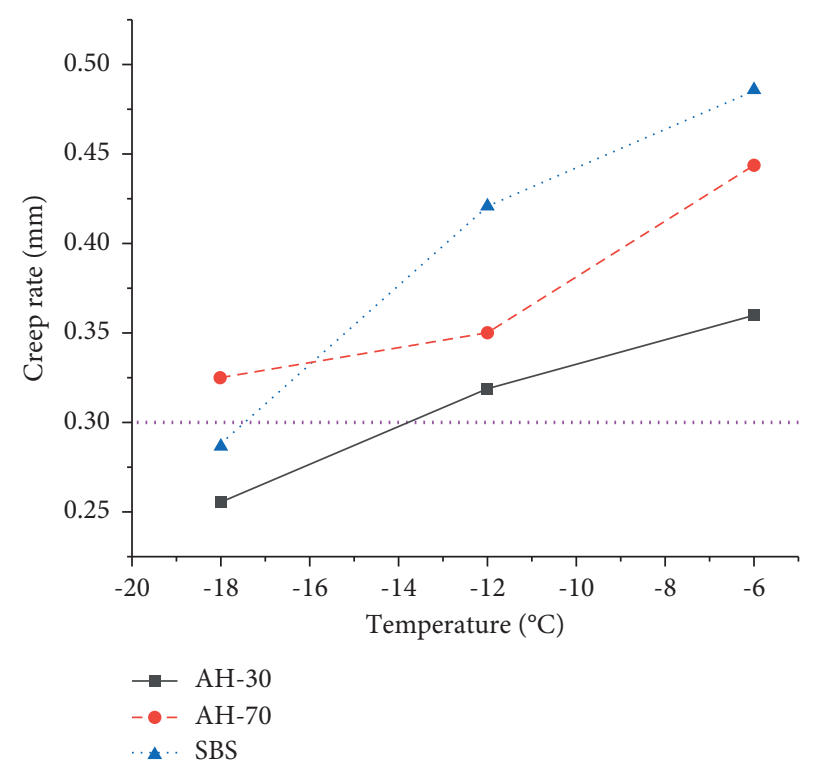

(b)

Figure 4: BBR test results of asphalt after aging: (a) stiffness modulus and (b) creep rate.

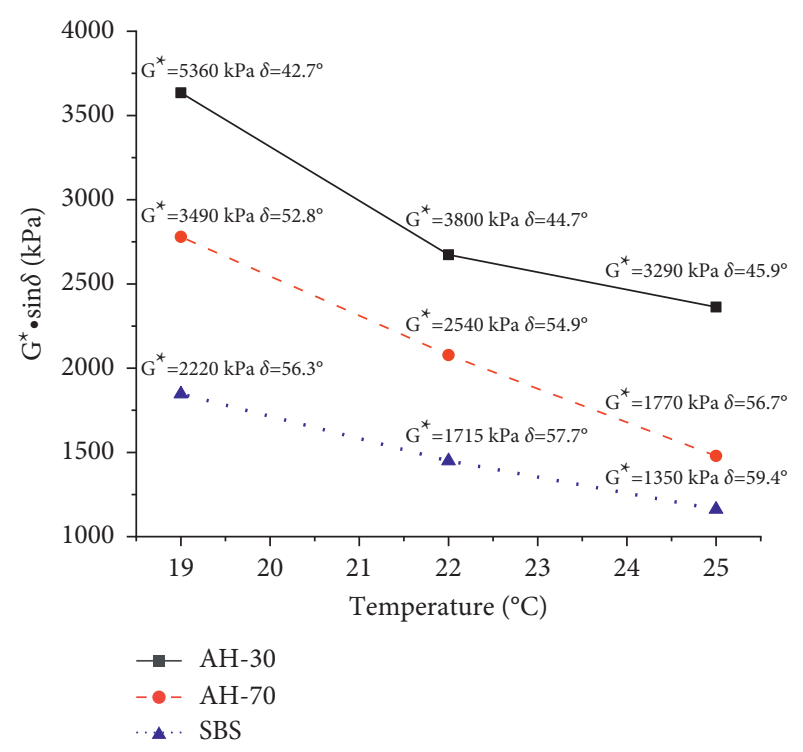

FIGURE 5: Fatigue test results of asphalt after PAV at different temperatures.

The results of the DS test show that the LTCR of the AH30 asphalt mixture is affected by the mixture gradation and test temperature. The LTCR of the AH-30 asphalt mixture is between that of the AH-70 asphalt mixture and SBS-modified asphalt mixture. The relationship of the tensile stress, tensile strain, and temperature is in the shape of peaks, and the peaks appear at $-5^{\circ} \mathrm{C}$. Therefore, it can be considered that $-5^{\circ} \mathrm{C}$ is the "demarcation temperature" of the $\mathrm{AH}-30$ asphalt mixture.

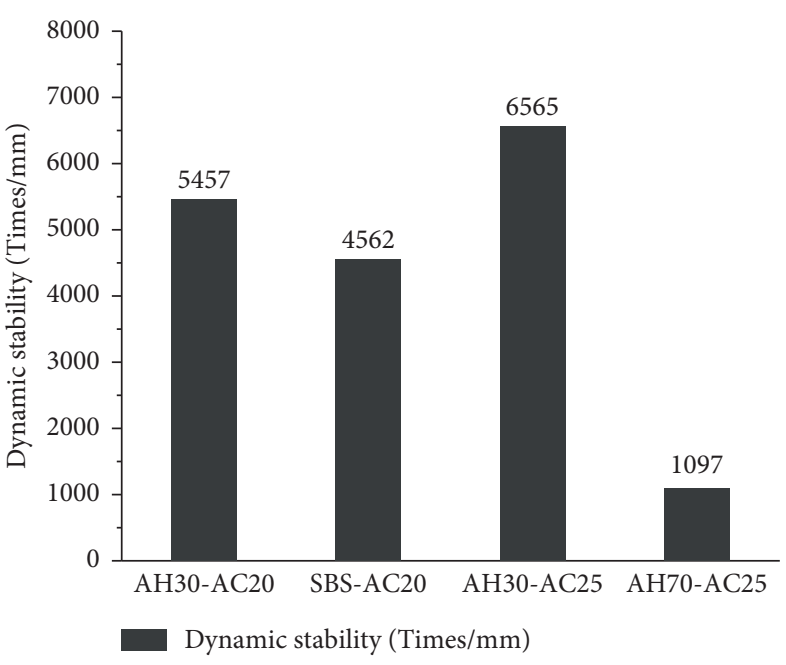

FIGURE 6: Rutting test results of four asphalt mixtures.

\subsubsection{Water Stability}

(1) Residual stability

The Marshall stability test results of the four asphalt mixtures are shown in Figure 9.

It can be seen from Figure 9 that compared to the other two asphalt mixtures, the AH-30 asphalt mixture has a more excellent $\mathrm{MS}_{0}$, which means that the WS of the AH-30 asphalt mixture is better.

(2) Freeze-thaw splitting strength ratio

The freeze-thaw splitting test results of the four asphalt mixtures are shown in Figure 10. 


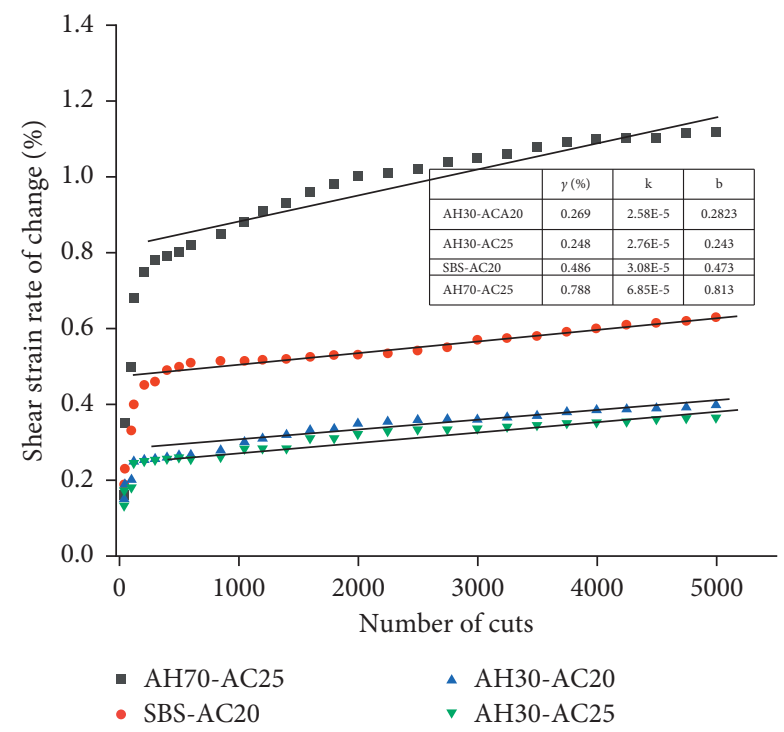

FIgURE 7: The test results of RSCH.

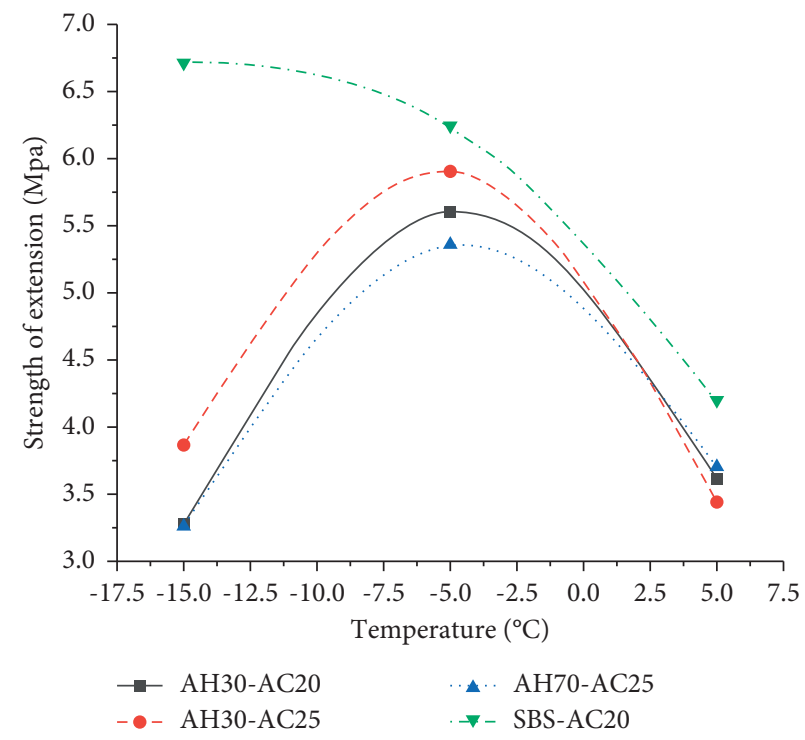

(a)

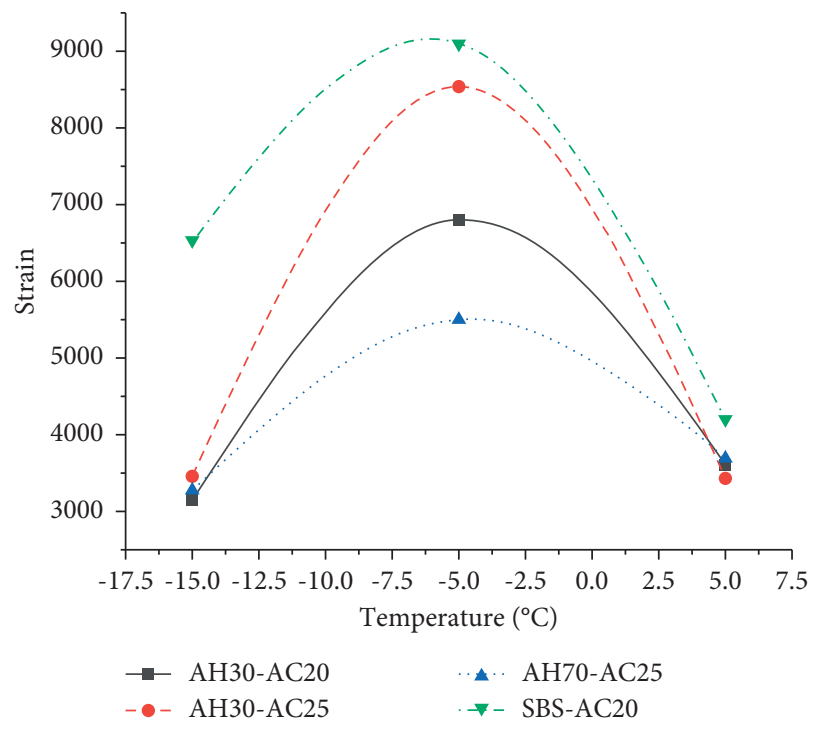

(b)

FIGURE 8: Direct stretching test results of the four asphalt mixtures under different test temperatures: (a) stress and (b) strain.

It can be seen from Figure 10 that the WS of asphalt mixtures can all meet the requirements (TSR $\geq 75 \%$ ). The freeze-thaw splitting strength ratios of the SBS \& AH30-AC20 asphalt mixtures are more resistant than those of AH30 \& AH70-AC25, showing that the asphalt mixture's freeze-thaw splitting strength ratio is not only related to the type of asphalt in the mixture but also the gradation. The WS of AH30AC20 is better than that of AH30-AC25, and the TSR of AH30-AC20 is approximately 9.1\% greater than that of $\mathrm{AH} 30-\mathrm{AC} 25$. When using $\mathrm{AH}-30$ asphalt as a binder, AC-20 is recommended.

4.2.4. Fatigue Property. The results of the three-point bending strength test are shown in Table 6.

The test results of the three-point bending fatigue are shown in Table 7.

From the test results in Table 6, under the same stress level, the fatigue life of the AH-30 asphalt mixture is much lower 


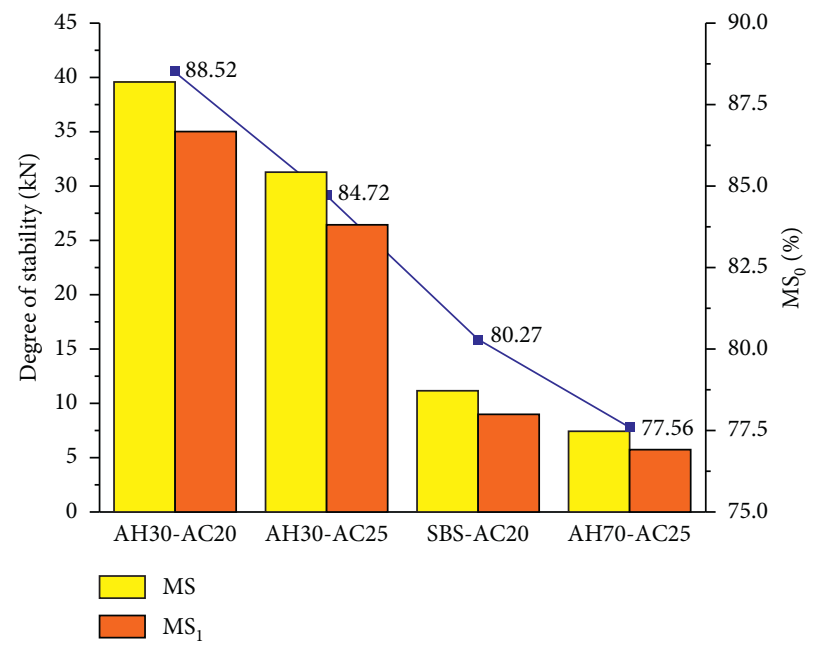

FIgURE 9: Marshall stability test results.

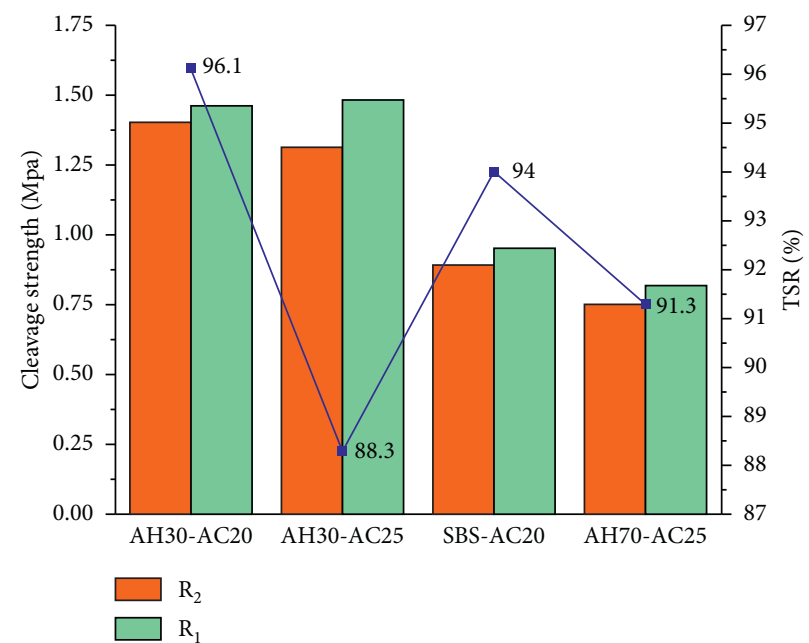

FIgURE 10: Test results of freeze-thaw splitting strength test.

TABLE 6: Test results of three-point bending strength test.

\begin{tabular}{lcc}
\hline Mixture & Load $(\mathrm{N})$ & Flexural-tensile strength (MPa) \\
\hline AH30-AC20 & 4638 & 12.33 \\
SBS-AC20 & 2353 & 6.26 \\
AH30-AC25 & 3784 & 10.30 \\
AH70-AC25 & 3188 & 8.48 \\
\hline
\end{tabular}

TABLE 7: Fatigue test results of three-point bending fatigue.

\begin{tabular}{|c|c|c|c|c|c|c|c|c|}
\hline \multirow[b]{2}{*}{ Stress ratio } & \multicolumn{2}{|c|}{ AH30-AC20 } & \multicolumn{2}{|c|}{ SBS-AC20 } & \multicolumn{2}{|c|}{ AH30-AC25 } & \multicolumn{2}{|c|}{ AH70-AC25 } \\
\hline & $\begin{array}{l}\text { Stress level } \\
(\mathrm{MPa})\end{array}$ & $\begin{array}{l}\text { Fatigue life } \\
\text { (times) }\end{array}$ & $\begin{array}{l}\text { Stress level } \\
(\mathrm{MPa})\end{array}$ & Fatigue life (times) & $\begin{array}{c}\text { Stress } \\
\text { level (MPa) }\end{array}$ & $\begin{array}{c}\text { Fatigue } \\
\text { life (times) }\end{array}$ & $\begin{array}{c}\text { Stress } \\
\text { level }(\mathrm{MPa})\end{array}$ & $\begin{array}{c}\text { Stress } \\
\text { level (MPa) }\end{array}$ \\
\hline \multirow{2}{*}{0.5} & \multirow{2}{*}{6.165} & 498 & \multirow{2}{*}{3.13} & 4343 & \multirow{2}{*}{5.15} & 1050 & \multirow{2}{*}{4.24} & 1111 \\
\hline & & 979 & & 5467 & & & & 1383 \\
\hline \multirow{2}{*}{0.4} & \multirow{2}{*}{4.932} & 1552 & \multirow{2}{*}{2.054} & 14155 & \multirow{2}{*}{4.12} & 7707 & \multirow{2}{*}{3.392} & 3684 \\
\hline & & 2294 & & 20187 & & 5431 & & 3316 \\
\hline \multirow{2}{*}{0.3} & \multirow{2}{*}{3.699} & 3224 & \multirow{2}{*}{1.878} & 21284 & \multirow{2}{*}{3.09} & 9475 & \multirow{2}{*}{2.544} & 7016 \\
\hline & & 5649 & & 30892 & & 8425 & & 9437 \\
\hline \multirow{2}{*}{0.2} & \multirow{2}{*}{2.466} & 65852 & \multirow{2}{*}{1.252} & 127746 & \multirow{2}{*}{2.06} & 63900 & \multirow{2}{*}{1.696} & 28634 \\
\hline & & 84165 & & 198230 & & 71547 & & 37312 \\
\hline \multirow{2}{*}{0.1} & \multirow{2}{*}{1.233} & 315516 & \multirow{2}{*}{0.626} & 912771 & \multirow{2}{*}{1.03} & 130905 & \multirow{2}{*}{0.848} & 164436 \\
\hline & & 382163 & & 987503 & & 110480 & & 201272 \\
\hline
\end{tabular}


than that of the SBS asphalt mixture and a little better than that of the AH-70 asphalt mixture. It is similar to the asphalt DSR test results, which also show that the fatigue performance of the asphalt mixture is mainly affected by asphalt.

From the experimental results, the fatigue performance of the AH-30 asphalt mixture is a problem worthy of attention.

\section{Conclusions}

In this research, the high-temperature stability, low-temperature crack resistance, fatigue performance, and water stability of AH-30 and mixtures were evaluated, and the conclusions drawn are as follows:

(1) The high-temperature resistance of $\mathrm{AH}-30$ is better than that of AH-70. AH-30 still has good hightemperature resistance after RTFOT aging. The WT test and $\mathrm{RSCH}$ test results show that the $\mathrm{AH}-30$ asphalt mixture (AH30-AC20/25) has excellent high-temperature resistance.

(2) The AH-30 and AH-70 asphalt mixture have similar LTCR. In areas where the lowest temperature in winter is not lower than $-10.5^{\circ} \mathrm{C}$, using $\mathrm{AH}-30$ asphalt as a binder can meet the requirements of the LTCR of asphalt mixture pavements.

(3) The fatigue resistance of $\mathrm{AH}-30$ asphalt and mixture is poor, which may be one reason why AH-30 asphalt pavement is prone to cracking. The fatigue resistance of AH-30 asphalt is still a problem worthy of attention.

(4) The water stability of the AH-30 asphalt mixture is equivalent to that of the other two asphalt mixtures, and both can meet the specification requirements. The WS of the AH-30 asphalt mixture is affected by the gradation of the mixture. The WS of AH30-AC20 is slightly better than that of AH30-AC25.

\section{Data Availability}

Some or all data, models, or codes that support the findings of this study are available from the corresponding author upon reasonable request.

\section{Conflicts of Interest}

The authors declare no conflicts of interest.

\section{Acknowledgments}

This research was funded by the programs of Wuhan Comprehensive Transportation Research Co. LTD (020200120441 and 020200-120442).

\section{References}

[1] B. Abdelhak, H.-C. Abdelmadjid, G. Mohamed, and G. Hamza, "Effect of recycled asphalt aggregates on the rutting of bituminous concrete in the presence of additive," Arabian Journal for Science and Engineering, vol. 41, no. 10, pp. 4139-4145, 2016.
[2] A. Norouzi, D. Kim, and Y. Richard Kim, "Numerical evaluation of pavement design parameters for the fatigue cracking and rutting performance of asphalt pavements," Materials and Structures, vol. 49, no. 9, pp. 3619-3634, 2016.

[3] Y. H. Wang, A. S. T. Wong, Y. Wen, and L. Chen, "Characterization of the distress modes and in situ material properties of Highway asphalt pavement with long service life," Journal of Performance of Constructed Facilities, vol. 30, no. 4, p. 11, 2016.

[4] M. R. Mohd Hasan, J. E. Hiller, and Z. You, "Effects of mean annual temperature and mean annual precipitation on the performance of flexible pavement using ME design," International Journal of Pavement Engineering, vol. 17, no. 7, pp. 647-658, 2016.

[5] F. Gu, Y. Zhang, C. V. Droddy, and R. Luo, "Development of a new mechanistic empirical rutting model for unbound granular material," Journal of Materials in Civil Engineering, vol. 28 , no. 8, p. 10, 2016.

[6] L. Zalimiene, A. Vaitkus, and D. Cygas, "Insights and findings following 11 Years of test road exploitation," Coatings, vol. 10, no. 12, p. 1161, 2020.

[7] S. Alber, B. Schuck, W. Ressel et al., "Modeling of surface drainage during the service life of asphalt pavements showing long-term rutting: a modular hydromechanical approach," Advances in Materials Science and Engineering, vol. 2020, p. 15, Article ID 8793652, 2020.

[8] Y. Ding and H. Wang, "Evaluation of hydroplaning risk on permeable friction course using tire-water-pavement interaction model," Transportation Research Record: Journal of the Transportation Research Board, vol. 2672, no. 40, pp. 408-417, 2018.

[9] P. Cong, Y. Zhang, and N. Liu, "Investigation of the properties of asphalt mixtures incorporating reclaimed SBS modified asphalt pavement," Construction and Building Materials, vol. 113, pp. 334-340, 2016.

[10] J. Yin and S. Wang, "Improving the performance of asphalt mixture by addition of short-thin wheat straw pieces," International Journal of Pavement Engineering, vol. 17, no. 6, pp. 528-541, 2016.

[11] N. Li, H. Zhan, X. Yu, and W. Tang, "Research on the high temperature performance of asphalt pavement based on field cores with different rutting development levels," Materials and Structures, vol. 54, no. 2, pp. 1-12, 2021.

[12] M. Liang, X. Xin, W. Fan, J. Zhang, H. Jiang, and Z. Yao, "Comparison of rheological properties and compatibility of asphalt modified with various polyethylene," International Journal of Pavement Engineering, vol. 22, no. 1, pp. 11-20, 2021.

[13] L. T. Geng, Y. Liua, Q. Xu, F. Han, X. Yu, and T. Qin, "Development of bio-based stabilizers and their effects on the performance of SBS-modified asphalt," Construction and Building Materials, vol. 271, p. 8, 2021.

[14] S. R. Karnati, D. Oldham, E. H. Fini, and L. Zhang, "Surface functionalization of silica nanoparticles with swine manurederived bio-binder to enhance bitumen performance in road pavement," Construction and Building Materials, vol. 266, p. 8, 2021.

[15] M. Jamal and F. Giustozzi, "Low-content crumb rubber modified bitumen for improving Australian local roads condition," Journal of Cleaner Production, vol. 271, p. 13, 2020.

[16] T. W. Johnson and L. Hashemian, "Laboratory evaluation of modified asphalt mixes using nanomaterial," Journal of Testing and Evaluation, vol. 49, no. 2, pp. 1020-1036, 2021. 
[17] X. Xin, Z. Yaoa, J. Shi et al., "Rheological properties, microstructure and aging resistance of asphalt modified with CNTs/PE composites," Construction and Building Materials, vol. 262, p. 11, 2020.

[18] S. Li, M. Fan, L. Xu, W. Tian, H. Yu, and K. Xu, "Rutting performance of semi-rigid base pavement in RIOHTrack and laboratory evaluation," Frontiers in Materials, vol. 7, p. 10, 2021.

[19] Y. Tong, B. Shen, J. Liu, Z. Yao, and W. Fang, "Preparation and evaluation of 30\# hard grade asphalt," Petroleum Science and Technology, vol. 35, no. 5, pp. 436-442, 2017.

[20] C. Wang, H. Wang, L. Zhao, and D. Cao, "Experimental study on rheological characteristics and performance of high modulus asphalt binder with different modifiers," Construction and Building Materials, vol. 155, pp. 26-36, 2017. 